\section{Effect of Raney Nickel on A/B Ring Fusion of Steroids}

Kleiderer and Kornfeld ${ }^{1}$ converted cholesterol, a 3-hydroxy- $\Delta^{5}$-steroid, into $\Delta^{4}$-cholestenone by heating cholesterol in toluene solution with Raney nickel in presence of cyclohexanone as hydrogen acceptor. Later, Romo ${ }^{2}$ described the formation of 3 -keto- $\Delta^{4}$ steroids from the 3 -hydroxy- $\Delta^{4}$-steroids by the action of the same catalyst in presence of acetone or methyl ethyl ketone as hydrogen acceptor.

Chakravarti and Robinson ${ }^{3}$ reported the conversion of strychnine into neostrychnine in presence of Raney nickel in boiling xylene solution. This iso. merization may be regarded as a dehydrogenation cum hydrogenation reaction. Proceeding similarly, in the present case, diosgenin was heated under reflux in xylene solution in presence of Raney nickel, but no appreciable change could be noticed. On repeating the experiment at a higher temperature, using a high-boiling solvent like $p$-cymene in place of xylene, diosgenin was found to be converted mostly into $\Delta^{4}$-dehydrotigogenone, $\mathrm{C}_{27} \mathrm{H}_{40} \mathrm{O}_{3}, \quad$ m.p. $185-186^{\circ}$, $[\alpha]_{D}^{23}$ nil $\left(\mathrm{CHCl}_{3}\right), \lambda_{\max }^{\text {alc. }} 243 \mathrm{~m} \mu$ (log $\left.\varepsilon 4.28\right)$, oxime m.p. $224^{\circ}$ (decomp.), semicarbazone m.p. $247^{\circ}$ (decomp.). When excess of Raney nickel was used in the above reaction, the major product was, however, found to be tigogenone, $\mathrm{C}_{27} \mathrm{H}_{42} \mathrm{O}_{3}$, m.p. 205-206 ${ }^{\circ}$, $[\alpha]_{D}^{32}-54^{\circ}\left(\mathrm{CHCl}_{3}\right)$, oxime m.p. $254-256^{\circ}$ (decomp.), semicarbazone m.p. $263^{\circ}$ (decomp.). Similarly, cholesterol was converted into $\Delta^{4}$-cholestenone in presence of the catalyst in boiling $p$-cymene solution. In presence of excess of the catalyst, the product obtained was cholestanone. Extending this reaction to other steroids, it was found that hecogenin gave hecogenone, stigmasterol gave $\Delta^{22}$-dehydrositostanone and $\beta$-sitosterol gave sitostanone. It is significant that in these transformations of the 3-hydroxy steroids into the 3-keto steroids, unlike those carried out by Kleiderer and Kornfeld ${ }^{1}$, and Romo ${ }^{2}$, no hydrogen acceptor like cyclohexanone or methyl othyl ketone was used.

All the compounds mentioned above have trans configuration with regard to the $A / B$ ring fusion. An interesting fact was observed when the reaction was applied to steroids having $A / B$-cis configuration. In all such cases the corresponding trans compounds were obtained, indicating the stereo-specificity of the effect of Raney nickel on the $A / B$ ring fusion. Thus both smilagenone and ep $i$-smilagenin ${ }^{4}$ under the above conditions gave tigogenone, sarsasapogenin gave neotigogenone and coprostanone gave cholestanone.

The work was financed by the Council of Scientific and Industrial Research, New Delhi. Thanks are due to Prof. L. F. Fieser, Converse Memorial Laboratory, Harvard University, and Prof. C. Djerassi, Wayne State University, for specimens of sarsasapogenin and tigogenin respectively.

Department of Chemistry, Bethune College, Calcutta 6.

$$
\text { D. Chakravarti }
$$

R. N. Chakravarti

Department of Chemistry,

School of Tropical Medicine, Calcutta 12.

1 Kleiderer, E. C., and Kornfeld, E. C., J. Org. Chem., 13, 455 (1948). 2 Romo, J., Bol. inst. quim. univ. nacl. auton. (Mexico), 4, 91 (1952). ${ }^{3}$ Chakravarti, R. N., and Robinson, R., J. Chem. Soc., 78 (1947).

4 Chakravarti, D., Chakravarti, R. N., and Mitra, M. N., Nature, 186, $236(1960)$.

\section{Elution Sequence as a Function of Temperature in Gas Chromatography}

THE main hydrocarbons present in the essential oil of hop (Humulus lupulus L. var. Fuggles) are myrcene, farnesene, caryophyllene and humulene ${ }^{1}$ (Fig. 1). In an attempt to find the best conditions for quantitative assay of these substances, hop oil hydrocarbon fraction was examined by gas chromatography over a range of column temperatures. It was noticed that when the temperature of analysis was decreased from $150^{\circ} \mathrm{C}$. to $125^{\circ} \mathrm{C}$., the separation of caryophyllene and farnesene, incomplete at $150^{\circ} \mathrm{C}$., became nonexistent at $125^{\circ} \mathrm{C}$. However, when the analysis was carried out at $175^{\circ} \mathrm{C}$. complete separation was achieved. This is the converse of the expected

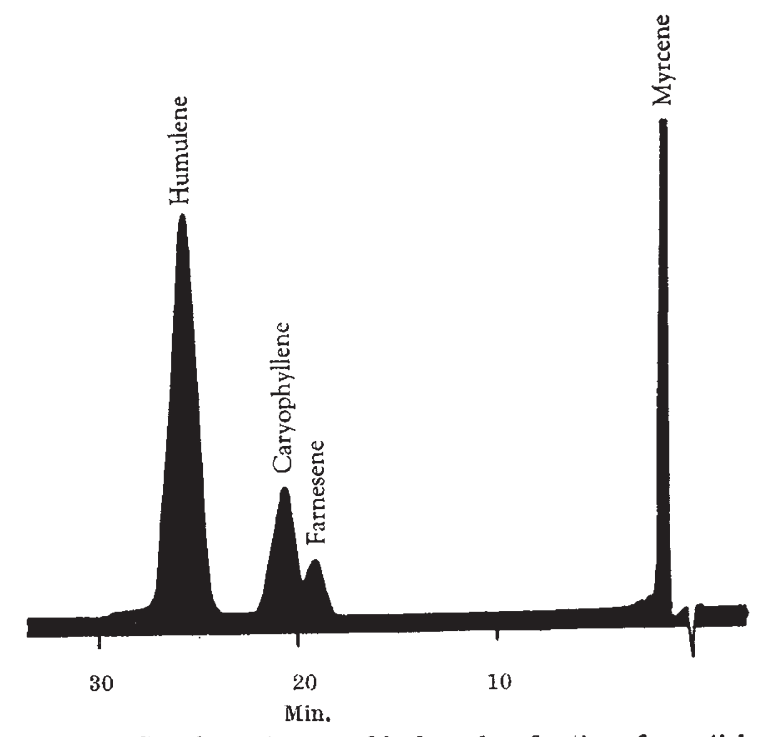

Fig. 1. Gas chromatogram of hydrocarbon fraction of essential oil of hops. $150^{\circ} \mathrm{C}$. 'Apiezon $L$ ' 10 per cent on 'Celite'. $50 \mathrm{ml}$./

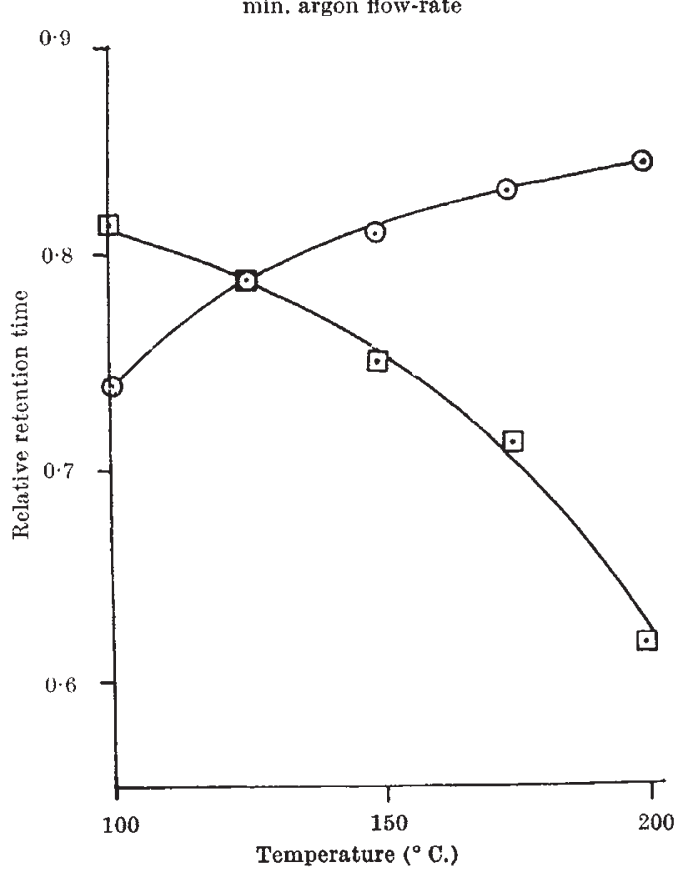

Fig. 2. Changes in relative retention times for farnesene, 